\title{
Early detection of anthracycline induced cardiotoxicity in asymptomatic patients with normal left ventricular systolic function: autonomic versus echocardiographic variables
}

G Tjeerdsma, M T Meinardi, W T A van der Graaf, M P van den Berg, N H Mulder, H J G M Crijns, E G E de Vries, D J van Veldhuisen

\begin{abstract}
Objective-To investigate left ventricular dysfunction in patients who had been treated with anthracycline based chemotherapy.

Methods-Autonomic function was compared with left ventricular diastolic function in 20 asymptomatic women with normal systolic function (left ventricular ejection fraction $(\mathrm{LVEF})>0.50)$ treated for breast cancer with high dose anthracycline based chemotherapy, and 20 age matched healthy controls. Left ventricular diastolic function was assessed echocardiographically by measuring the early peak flow velocity to atrial peak flow velocity ratio, isovolumic relaxation time, and deceleration time. Heart rate variability analysis was assessed for time domain and frequency domain parameters.
\end{abstract}

Results-The mean (SD) age of the patients was 45 (7) years and the mean LVEF was $0.59(0.06)$. The time interval after the end of chemotherapy was 29 (27) months. One or more diastolic variables were abnormal in $50 \%$ of the patients. Heart rate variability was abnormal in $85 \%$ of patients. Mean values of both time domain and frequency domain parameters were decreased $(p<0.05)$, in particular the parasympathetic indices.

Conclusions-Autonomic impairment occurs in a large proportion of asymptomatic patients with normal systolic left ventricular function after high dose anthracycline based chemotherapy. In particular, heart rate variability analysis may be a sensitive tool to identify the first signs of cardiotoxicity in these patients.

(Heart 1999;81:419-423)

Keywords: anthracycline; cardiotoxicity; heart rate variability; echocardiography; chemotherapy

Department of Internal Medicine/Medical Oncology, University Hospital Groningen M T Meinardi

W T A van der Graaf

N H Mulder

E G E de Vries

Correspondence to:

Dr van Veldhuisen.

Accepted for publication 25 November 1998

Anthracycline induced cardiotoxicity, which may ultimately lead to congestive heart failure, is a well known problem in the treatment of cancer and limits the therapeutic use of this group of effective antineoplastic agents. ${ }^{12}$ However, from several studies it is apparent that the inclusion of anthracyclines in chemotherapeutic regimens lessens the risk of disease progression and mortality. ${ }^{3}$ As a result, anthracyclines have been used increasingly in recent years, not only in patients with metastatic breast cancer but also in the adjuvant setting. ${ }^{56}$ Thus it is likely that cardiotoxicity will occur more often in the future. To optimise anthracycline treatment in the individual patient and to prevent cardiac injury, early detection of cardiotoxicity is needed. In many cancer treatment protocols, cardiotoxicity is assessed by measuring left ventricular ejection fraction (LVEF) by radionuclide ventriculography. However, LVEF is known to be a rather insensitive measure of early cardiac damage ${ }^{7}$ and several studies suggest that in anthracycline induced cardiotoxicity diastolic changes precede systolic dysfunction, ${ }^{89}$ as in other forms of heart disease. ${ }^{1011}$ Thus the assessment of diastolic function may be a better method of early detection of cardiotoxicity.

Another method of detecting cardiotoxicity at an early stage may be the assessment of autonomic function. Although there has been increasing recognition in recent years of the role of autonomic imbalance in the pathogenesis of heart failure, ${ }^{12}{ }^{13}$ up to now its value in anthracycline induced cardiotoxicity has hardly been studied. Autonomic changes have been shown to arise at an early stage of left ventricular dysfunction and to increase with the severity of the disease. ${ }^{13-15}$ Heart rate variability analysis is a commonly used, reliable, non-invasive tool for assessing autonomic function. ${ }^{16}$

In this study we analysed a group of asymptomatic female patients without left ventricular systolic dysfunction (LVEF > 0.50), who had been treated for locally advanced or metastatic breast cancer with high dose anthracycline based chemotherapy and, in most cases, with regional radiotherapy. We hypothesised that there would be echocardiographic evidence of diastolic dysfunction and impairment of heart rate variability parameters in this population.

\section{Methods}

PATIENT SELECTION
Asymptomatic (female) patients with locally advanced or metastatic breast cancer, who had been treated with anthracyclines (doxorubicin, epirubicin, mitoxantrone), were eligible for the study. These patients partly participated in a Dutch national randomised trial. ${ }^{17}$ None of these patients had a history of cardiac disorders, or was on cardiovascular drug treatment. In none of the patients was there evidence of diabetes mellitus or hypertension. All patients 
Table 1 Patient characteristics of the study population

\begin{tabular}{|c|c|c|c|c|c|c|}
\hline \multirow[b]{2}{*}{ Patient } & \multirow[b]{2}{*}{ Age (years) } & \multirow[b]{2}{*}{$L V E F$} & \multirow{2}{*}{$\begin{array}{l}\text { Time since } \\
\text { chemotherapy } \\
\text { (months) }\end{array}$} & \multicolumn{3}{|l|}{ Treatment } \\
\hline & & & & $\begin{array}{l}\text { Induction } \\
\text { chemotherapy }\end{array}$ & $\begin{array}{l}\text { Ablative } \\
\text { chemotherapy }\end{array}$ & $\begin{array}{l}\text { Radiotherapy, chest } \\
\text { side/Gy }\end{array}$ \\
\hline 1 & 30 & 0.70 & 4 & C & TMM & $\mathrm{L} / 50$ \\
\hline 2 & 51 & 0.54 & 38 & B & MM & $\mathrm{R} / 50$ \\
\hline 3 & 40 & 0.52 & 48 & $\mathrm{C}$ & TMM & $\mathrm{L} / 70$ \\
\hline 4 & 51 & 0.53 & 66 & B & $\mathrm{TM}$ & $\mathrm{L} / 50$ \\
\hline 5 & 47 & 0.59 & 6 & C & TMM & $-1-$ \\
\hline 6 & 43 & 0.73 & 8 & A & CTC & $\mathrm{R} / 50$ \\
\hline 7 & 55 & 0.60 & 20 & A & CTC & $\mathrm{L} / 50$ \\
\hline 8 & 40 & 0.57 & 28 & A & CTC & $\mathrm{L} / 50$ \\
\hline 9 & 54 & 0.60 & 13 & A & CTC & $\mathrm{R} / 50$ \\
\hline 10 & 51 & 0.64 & 30 & A & CTC & $\mathrm{R} / 50$ \\
\hline 11 & 51 & 0.60 & 19 & A & СTC & $\mathrm{L} / 50$ \\
\hline 12 & 48 & 0.65 & 8 & A & CTC & $\mathrm{R} / 50$ \\
\hline 13 & 50 & 0.65 & 17 & A & CTC & $\mathrm{R} / 32$ \\
\hline 14 & 47 & 0.63 & 34 & A & CTC & $\mathrm{L} / 50$ \\
\hline 15 & 34 & 0.62 & 21 & A & CTC & $\mathrm{R} / 50$ \\
\hline 16 & 49 & 0.65 & 1 & A & CTC & $-1-$ \\
\hline 17 & 49 & 0.61 & 108 & B & $\mathrm{MM}$ & $-1-$ \\
\hline 18 & 39 & 0.61 & 54 & B & $\mathrm{TM}$ & $\mathrm{R} / 50$ \\
\hline 19 & 43 & 0.60 & 2 & A & CTC & $\mathrm{L} / 50$ \\
\hline 20 & 46 & 0.52 & 54 & B & MT & $\mathrm{L} / 50$ \\
\hline Mean (SD) & $45(7)$ & $0.59(0.06)$ & $29(27)$ & & & \\
\hline
\end{tabular}

A, chemotherapy regimen A; B, chemotherapy regimen B; C, chemotherapy regimen C; CTC, cyclophosphamide + thiotepa + carboplatin; L, left side of the chest; LVEF, left ventricular ejection fraction; MM, mitoxantrone + melphalan; R, right side of the chest; $\mathrm{TM}$, thiotepa + mitoxantrone; TMM, thiotepa + mitoxantrone + melphalan.

underwent cardiac evaluation, which included history and physical examination, radionuclide ventriculography to determine LVEF, echocardiography, and heart rate variability analysis. Only patients with an LVEF $>0.50$ were included. Age matched healthy women served as a control group. The study was approved by the medical ethics committee of the University Hospital Groningen. All patients gave informed consent.

\section{CHEMOTHERAPY REGIMEN}

Patients received one of the following three possible chemotherapy regimens (table 1 ):

(A) Four courses of 5-fluorouracil $(500 \mathrm{mg} /$ $\left.\mathrm{m}^{2}\right)$, epirubicin $\left(90 \mathrm{mg} / \mathrm{m}^{2}\right)$, and cyclophosphamide $\left(500 \mathrm{mg} / \mathrm{m}^{2}\right)$ for induction chemotherapy, followed by cyclophosphamide $\left(6000 \mathrm{mg} / \mathrm{m}^{2}\right)$, thiotepa $(480 \mathrm{mg} /$ $\left.\mathrm{m}^{2}\right)$, and carboplatin $\left(1.6 \mathrm{~g} / \mathrm{m}^{2}\right)$ as ablative chemotherapy. ${ }^{17}$

(B) Six courses of 5-fluorouracil $(1500 \mathrm{mg} /$ $\left.\mathrm{m}^{2}\right)$, methotrexate $\left(1500 \mathrm{mg} / \mathrm{m}^{2}\right)$ alternating with doxorubicin $\left(50 \mathrm{mg} / \mathrm{m}^{2}\right)$, and vincristine $(2 \mathrm{mg}$ ) for induction chemotherapy, followed by mitoxantrone (60 $\mathrm{mg} / \mathrm{m}^{2}$ ) plus melphalan $180 \mathrm{mg} / \mathrm{m}^{2}$ or mitoxantrone $50 \mathrm{mg} / \mathrm{m}^{2}$ plus thiotepa $(800$ $\mathrm{mg} / \mathrm{m}^{2}$ ) as ablative chemotherapy. ${ }^{18}$

(C) Three courses of cyclophosphamide $\left(1500 \mathrm{mg} / \mathrm{m}^{2}\right)$, epirubicin $\left(80 \mathrm{mg} / \mathrm{m}^{2}\right)$, 5-fluorouracil $\left(1500 \mathrm{mg} / \mathrm{m}^{2}\right)$, three courses of cyclophosphamide $(1500 \mathrm{mg} /$ $\left.\mathrm{m}^{2}\right)$, 5-fluorouracil $\left(600 \mathrm{mg} / \mathrm{m}^{2}\right)$ and methotrexate $\left(1500 \mathrm{mg} / \mathrm{m}^{2}\right)$, and two courses of high dose epirubicin (180 $\mathrm{mg} / \mathrm{m}^{2}$ ) for induction chemotherapy, followed by thiotepa $\left(800 \mathrm{mg} / \mathrm{m}^{2}\right)$ and subsequently mitoxantrone $\left(60 \mathrm{mg} / \mathrm{m}^{2}\right)$ and melphalan $\left(180 \mathrm{mg} / \mathrm{m}^{2}\right)$ as ablative chemotherapy.

Regimen A contains intermediate dose anthracyclines, regimens $\mathrm{B}$ and $\mathrm{C}$ contain high dose anthracyclines (table 1).
ECHOCARDIOGRAPHY

To assess diastolic function, echocardiography was performed using a Vingmed CFM 800 instrument (Sonotron, Horten, Norway), equipped with a $3.25 \mathrm{MHz}$ transducer. Gain setting was optimised to a level just below background noise. Cross sectional images were obtained in left ventricular parasternal long axis and short axis views, and apical four chamber and two chamber long axis views. ${ }^{19-21}$ Left ventricular end diastolic diameter (normal mean (SD) value $47(4) \mathrm{mm}$ ) and posterior wall diastolic thickness (normal mean value $9 \mathrm{~mm}$ (range 6 to 11)) were measured as described by Weyman. ${ }^{22}$ For the analysis of diastolic function, early peak flow velocity/ atrial peak flow velocity (E/A ratio), deceleration time, and isovolumic relaxation time were measured. ${ }^{93}$ As described in previous papers, normal values are 1.9 (range 0.7 to 3.1 ), 179 ms (range 139 to 219 ), and $76 \mathrm{~ms}$ (range 54 to 98) for age matched healthy women, respectively. ${ }^{24}$

\section{HEART RATE VARIABILITY}

All patients underwent 24 hour Holter monitoring. The results were compared with healthy age matched women. The data were recorded using a Marquette 8000 Holter system (Marquette Electronics Inc, Milwaukee, Wisconsin, USA). Tapes with more than $15 \%$ noise overall were excluded, and heart rate variability was analysed only when sinus rhythm was present. Time and frequency domain parameters were calculated as previously described in detail from our institution. ${ }^{15} 25$

Briefly, time and frequency domain parameters were calculated from the time series of RR intervals and were computed over 288 segments of five minutes for a total of 24 hours recording. The following time domain parameters were measured: standard deviation of heart period (SDNN, ms), standard deviation of five minute mean values of NNs for each five 
minute interval (SDANN, ms), proportion of successive NN differences $>50 \mathrm{~ms}$ (PNN50, $\%$ ), and root mean square successive difference of NN intervals (rMSSD, ms). Frequency domain analysis was performed by using discrete Fourier transformation. Low frequencies (LF, 0.04 to $0.15 \mathrm{~Hz}$ ), high frequencies ( $\mathrm{HF}, 0.15$ to $0.4 \mathrm{~Hz}$ ), and total power (TP, 0.0033 to $0.4 \mathrm{~Hz}$ ) were calculated.

\section{STATISTICAL ANALYSIS}

All values are expressed as mean (SD). The two tailed independent non-parametric MannWhitney $\mathrm{U}$ test was applied to compare the outcome of autonomic variables in patients and age matched healthy controls. A p value $<0.05$ was considered statistically significant.

\section{Results}

STUDY POPULATION

Twenty two consecutive asymptomatic patients attending the outpatient clinic of the department of medical oncology for follow up were referred for the study. Two patients were found to have an LVEF of $<0.50$ (0.39 and 0.43 , respectively) and these were excluded. The remaining 20 patients form the present study population. Their characteristics are summarised in table 1 . Their mean age was 45 years (range 30 to 55), the mean (SD) LVEF was 0.59 (0.06), and the interval from discontinuation of anthracycline treatment to evaluation was 29 (27) months.

TREATMENT PROTOCOL

Twelve patients received regimen $\mathrm{A}$, five patients regimen $B$, and three patients regimen C (table 1). Eight patients received mitoxantrone in regimens B and C. Seventeen of the 20 patients received regional radiotherapy, 32-70 Gy, after chemotherapy. In all cases irradiation was given with 4-6 $\mathrm{MeV}$ photons from a linear accelerator in fractions of 2 Gy to the breast or chest wall, the supraclavicular, axillary, and internal mammary lymph nodes. In nine patients the irradiation was given to the left side of the chest.

\section{ECHOCARDIOGRAPHY}

The mean E/A ratio was 0.98 (0.05), range 0.6 to 1.4 , and 10 of the 20 patients had an abnormal value (E/A ratio < 1.9$)$. The mean deceleration time was 180 (13) ms, range 96 to 338; the result was abnormal in three patients and all three also had an abnormal E/A ratio. Mean isovolumic relaxation time was 74.0 (3.5) $\mathrm{ms}$, range 48 to 88 ; the result was abnormal in only one patient who also had an abnor$\mathrm{mal} \mathrm{E} / \mathrm{A}$ ratio. Therefore at least one of three diastolic variables was abnormal in 10 of the 20 patients, and 10 patients had no abnormalities. Left ventricular end diastolic diameter and posterior wall diastolic thickness were normal in all patients after treatment.

HEART RATE VARIABILITY

Eleven patients had no significant ventricular arrhythmias. In three patients asymptomatic non-sustained ventricular tachycardia (maximum frequency 187 beats $/ \mathrm{min}$, maximum

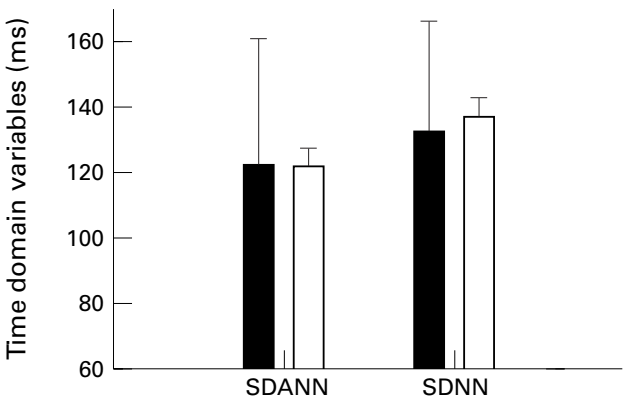

Figure 1 Impact on autonomic balance for patients (solid) $v$ age matched healthy controls (open) (time domain HRV parameters). SDANN, standard deviation of the averages of normal $R R$ intervals in all five minute segments of a complete $24 \mathrm{~h}$ recording; SDNN, standard deviation of all normal RR intervals. Error bars $=S D$.

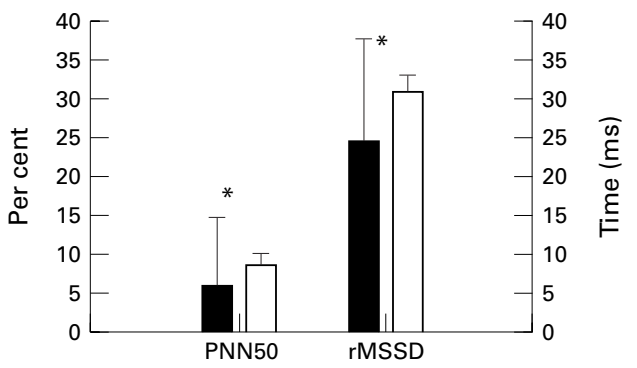

Figure 2 Autonomic impairment after anthracycline treatment for patients with breast cancer (solid) $v$ age matched healthy controls (open) (time domain HRV parameters). All parameters were significantly lower in patients. pNN50, percentage of differences between successive normal RR intervals greater than $50 \mathrm{~ms}$; $r M S S D$, the square root of the mean of the squared differences between successive normal RR intervals. Error bars $=S D .{ }^{\star} p<0.05$.

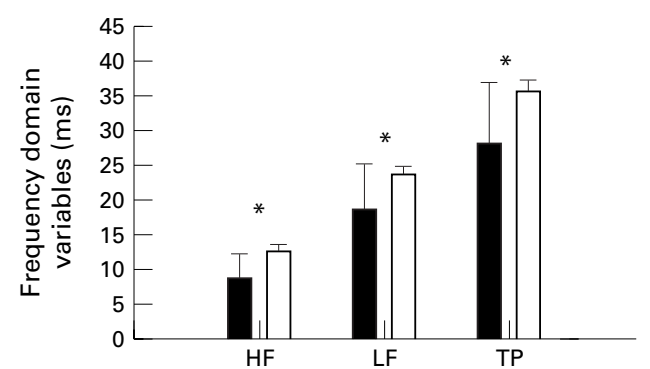

Figure 3 Impact on autonomic balance for anthracycline treated patients with breast cancer (solid) $v$ age matched controls (open) (frequency domain heart rate variability parameters). HF, high frequency; $L F$, low frequency; $T P$, total power. Error bars $=S D$. ${ }^{\star} p<0.01$.

duration 1 second) were observed. Nonsustained supraventricular tachycardia (maximum frequency 107 beats/min, maximum duration 2 seconds) was detected in six patients. Of the time domain parameters, SDANN and SDNN were not significantly different between patients and healthy controls, $\mathrm{p}<0.90$ (fig 1 ).

In contrast, PNN50 and rMSSD were significantly lower in patients than in healthy controls (fig 2). For patients and healthy controls the mean PNN50 was 5.9 (8.9)\% and $8.5(1.5) \%$, respectively $(\mathrm{p}<0.05)$. The mean rMSSD was 24.7 (13.2) $\mathrm{ms}$ in patients and $30.9(2.0) \mathrm{ms}$ in controls $(\mathrm{p}<0.05)$.

Mean frequency domain parameters of heart rate variability were decreased for all variables; low frequency, high frequency, and total power 
spectrum were lower in patients than in controls (fig 3), $\mathrm{p}<0.01$. Mean $\mathrm{HF}$ was 8.7 (3.5) $\mathrm{ms}$ for patients $v 12.6(0.9) \mathrm{ms}$ for controls. Mean LF was 18.4 (6.6) $\mathrm{ms}$ for patients $v 23.7(1.1) \mathrm{ms}$ for controls. For the TP spectrum, the mean outcomes were 28.1 (8.7) $\mathrm{ms}$ and $35.6(1.7) \mathrm{ms}$, respectively.

Overall, $15 \%$ of the patients had normal autonomic function. However, in 17 of the 20 patients $(85 \%)$ all three frequency domain parameters were abnormal. The time domain parameters PNN50 and rMSSD were abnormal in the same group of patients. When the group of patients was subdivided into intermediate dose anthracycline containing chemotherapy (regimen A) versus high dose chemotherapy (regimens B or C), no differences were observed for all (time and frequency domain) heart rate variability parameters. Comparison of irradiation of the right versus the left side of the chest wall showed no differences for any of the heart rate variability time and frequency domain parameters.

\section{Discussion}

The results of this study show that asymptomatic breast cancer patients with normal systolic left ventricular function, treated with high dose anthracycline based chemotherapy and radiotherapy, have a high prevalence of autonomic impairment. While diastolic dysfunction was present in a large number of patients $(50 \%)$, an even larger proportion (85\%) of patients had autonomic abnormalities, as demonstrated by heart rate variability analysis. These findings suggest that heart rate variability analysis may be a more sensitive tool than assessment of systolic function for the early detection of anthracycline induced cardiac damage, although the specificity of abnormal heart rate variability is not known.

As anthracyclines are increasingly used in adjuvant chemotherapy regimens for breast cancer, and the indications for adjuvant chemotherapy have increased, ${ }^{5}{ }^{6}$ the development of cardiac dysfunction is likely to be an increasingly important clinical problem in these patients.

The risk of inducing cardiac abnormalitiesincluding the development of heart failureeven years after treatment as a result of anthracycline therapy has been recognised for a long time. ${ }^{122226}$ Suitable tests are needed to adapt chemotherapy schedules and monitor supportive cardiac treatment. However, a highly sensitive screening method that is capable of predicting cardiac dysfunction is still to be found.

Currently, LVEF measured by radionuclide ventriculography or echocardiography is used to detect or exclude cardiac damage in cancer patients treated with anthracyclines. However, LVEF measurement is a relatively insensitive tool for detecting anthracycline induced cardiotoxicity at an early stage. ${ }^{7}$ This is largely because no considerable change in systolic function occurs until a critical amount of morphological damage has been taken place. After this point deterioration proceeds rapidly and the prognosis is poor.
In our patient group we observed a high prevalence of diastolic abnormalities, although LVEF was normal. This suggests that diastolic impairment precedes systolic dysfunction, in agreement with previous reports. ${ }^{89}$ Thus, in comparison with LVEF, the assessment of diastolic function by echocardiography may show cardiotoxicity in an earlier stage.

A striking finding in our study was the high prevalence of autonomic dysfunction, as measured by heart rate variability analysis. As in other forms of cardiac pathology, the role of autonomic changes in the pathogenesis of heart failure is increasingly recognised. Baroreceptor control of heart rate, sympathetic traffic, and heart rate variability have shown to be impaired in patients with mild or moderate heart failure. ${ }^{1527}$ Heart rate variability analysis has been shown to detect left ventricular dysfunction in an early stage, ${ }^{13}{ }^{14}$ and may also be of prognostic value in heart failure. ${ }^{15}$ An important marker in this respect is a reduction in parasympathetically mediated heart rate variability. ${ }^{12}$

Heart rate variability analysis in our patient group showed that the time domain parameters related to parasympathetic activity (rMSSD, PNN50) were particularly likely to be abnormal; in addition, the frequency domain parameters showed a similar pattern of autonomic change.

These results are in agreement with the study of Postma et $a l^{28}$ who examined autonomic balance by heart rate variability analysis in long term survivors of malignant bone tumours treated with anthracyclines. Those patients also had particularly reduced parasympathetic activity, which correlated with the cumulative anthracycline dose.

It is generally believed that anthracyclines do not have direct toxic effects on the autonomic nervous system and thus the observed abnormalities in our study would be considered secondary to left ventricular dysfunction. It is thought that direct injury to the myocytes plays a major role in anthracycline induced cardiotoxicity. Thus the observed abnormalities in heart rate variability in our study may be secondary to myocardial damage. However, if chemotherapeutic agents have a direct effect on neurones, the changes in heart rate variability may not reflect cardiac changes alone.

STUDY LIMITATIONS

The number of patients in this exploratory study was rather small and the group of patients was rather heterogeneous with respect to chemotherapy regimens, irradiation, and time after discontinuation of chemotherapy. Given the observational design of the study, while the data can be used to generate new hypotheses, obviously they need to be confirmed in a larger, prospective study with a homogeneous population. Such a study is needed to clarify the prognostic role of the autonomic changes and to determine whether these changes may precede the diastolic changes, as suggested by the higher prevalence of autonomic changes than diastolic abnormalities in our study. Further, since our 
patients were all fit and normally active, the observed abnormalities appear to be related to previous anthracycline based chemotherapy, although it cannot be excluded that a more sedentary lifestyle resulting from the disease may lead to some deconditioning.

CLINICAL IMPLICATIONS

We studied asymptomatic patients with preserved systolic left ventricular function who had undergone anthracycline drug treatment for breast cancer. A large proportion had indications of cardiac toxicity. Careful monitoring is warranted, since symptoms might occur over time in many of these patients. Whether early pharmacological intervention might be beneficial is unknown and needs further study.

This research was supported by a grant from the University Hospital Groningen.

1 Von Hoff DD, Layard MW, Basa P, et al. Risk factors for doxorubicin-induced congestive heart failure. Ann Intern Med 1979;91:710-17.

2 Praga C, Beretta G, Vigo PL, et al. Adriamycin cardiotoxicity: a

3 Tomiak E, Piccart M, Mignolet $\mathrm{F}$, et al. Characterisation of complete responders to ion chemotherapy for advanced breast cancer: a retrospective EORTC breast group study. Eur 7 Cancer 1996;32A:1876-87.

4 Bonadonna G, Zambetti M, Valagussa P. Sequential or alternating doxorubicin and CMF regimens in breast cancer with more than three positive nodes. Ten-year results. fAMA 1995;273:542-7.

5 Anonymous. Adjuvant systemic therapy for women with node-negative breast cancer. The Steering Committee on Clinical Practice Guidelines for the Care and Treatment of Breast Cancer. Can Med Assoc f 1998;158(suppl 3):S4351.

6 Fisher B, Dignam J, Wolmark N, et al. Tamoxifen and chemotherapy for lymph node-negative, estrogen receptorpositive breast cancer. 7 Natl Cancer Inst 1997;89:1673-82

7 McKillop JH, Bristow MR, Goris ML, et al. Sensitivity and specificity of radionuclide ejection fractions in doxorubicin cardiotoxicity. Am Heart f 1983;106:1048-56.

8 Marchandise B, Schroeder E, Bosly A, et al. Early detection of doxorubicin cardiotoxicity: interest of Doppler echocardiographic analysis of left ventricular filling dynamics. $A m$ diographic analysis of left

9 Stoddard MF, Seeger J, Liddell NE, et al. Prolongation of isovolumetric relaxation time as assessed by Doppler echocardiography predicts doxorubicin-induced systolic dysfunction in humans. 7 Am Coll Cardiol 1992;20:62-9.

10 Kuecherer HF, Ruffmann K, Schaefer E, et al. Doppler echocardiographic assessment of left ventricular filling dynamics in patients with coronary heart disease and normal systolic function. Eur Heart $\mathcal{F}$ 1988;9:649-56.
11 Zarich SW, Arbuckle BE, Cohen LR, et al. Diastolic abnormalities in young asymptomatic diabetic patients assessed 1988;12:114-20.

12 Binkley PF, Nunziata E, Haas GJ, et al. Parasympathetic withdrawal is an integral component of autonomic imbalance in congestive heart failure: demonstration in human subjects and verification in a paced canine model of ventricular failure. F Am Coll Cardiol 1991;18:464-72.

13 Ishise $\mathrm{H}$, Asanoi $\mathrm{H}$, Ishizaka $\mathrm{S}$, et al. Time course of sympathovagal imbalance and left ventricular dysfunction in conscious dogs with heart failure. $\mathcal{F} \mathrm{Appl}$ Physiol 1998;84:1234-41.

14 Eaton GM, Cody RJ, Nunziata E, et al. Early left ventricular dysfunction elicits activation of sympathetic drive and attenuation of parasympathetic tone in the paced canine model of congestive heart failure. Circulation 1995;92:55561 .

15 Brouwer J, van Veldhuisen DJ, Man in 't Veld AJ, et al. Prognostic value of heart rate variability during long-term follow-up in patients with mild to moderate heart failure. The Dutch Ibopamine Multicenter Trial Study Group. $\mathcal{F}$ Am Coll Cardiol 1996;28:1183-9.

16 Akselrod S, Gordon D, Ubel FA, et al. Power spectrum analysis of heart rate fluctuation: a quantitative probe of beat-to-beat cardiovascular control. Science 1981;213:2202 .

17 de Vries EG, ten Vergert EM, Mastenbroek CG, et al. Breast cancer studies in the Netherlands. Lancet 1996;348:407-8.

18 de Graaf H, Willemse PH, Sleijfer DT, et al. Effective conditioning regimen for premenopausal patients with advanced breast cancer. Anticancer Res 1994;14:2799-804.

19 Spain MG, Smith MD, Grayburn PA, et al. Quantitative assessment of mitral regurgitation by Doppler color flow imaging: angiographic and hemodynamic correlations. $\mathcal{F}$ Am Coll Cardiol 1989;13:585-90.

20 Perry GJ, Helmcke F, Nanda NC, et al. Evaluation of aortic insufficiency by Doppler color flow mapping. 7 Am Coll Cardiol 1987;9:952-9.

21 Pieper EP, Hellemans IM, Hamer HP, et al. Biplane transesophageal color-flow Doppler imaging in assessing severity of mitral regurgitation: influence of hemodynamic circumstances and mechanism of regurgitation. 7 Cardiothorac Vasc Anesth 1996;10:748-55.

22 Weyman AE Principles and practice of echocardiography, 2nd ed. Philadelphia: Lea and Febiger, 1994:1289-95.

23 Taylor R, Waggoner AD. Doppler assessment of left ventricular diastolic function: a review. $7 \mathrm{Am}$ Soc Echocardiogr 1992;5:603-12.

24 Cohen GI, Pietrolungo JF, Thomas JD, et al. A practical guide to assessment of ventricular diastolic function using Doppler echocardiography. F Am Coll Cardiol 1996;27: 1753-60

25 Tuininga YS, Crijns HJ, Brouwer J, et al. Evaluation of importance of central effects of atenolol and metoprolol measured by heart rate variability during mental performance tasks, physical exercise, and daily life in stable postinfarct patients. Circulation 1995;92:3415-23.

26 Steinherz LJ, Steinherz PG, Tan CT, et al. Cardiac toxicity 4 to 20 years after completing anthracycline therapy. FAMA 991:266:1672-7.

27 Grassi G, Seravalle G, Cattaneo BM, et al. Sympathetic activation and loss of reflex sympathetic control in mild congestive heart failure. Circulation 1995;92:3206-11.

28 Postma A, Bink-Boelkens MT, Beaufort-Krol GC, et al. Late cardiotoxicity after treatment for a malignant bone tumor. Med Pediatr Oncol 1996;26:230-7. 